\title{
PREVALENCE AND RISK FACTORS OF DEPRESSIVE SYMPTOMS AMONG INSTITUTIONALIZED ELDERLY IN SABAH, MALAYSIA BORNEO
}

\author{
Helmy Sajali ${ }^{1,2}$, Syed Sharizman Syed Abdul Rahim ${ }^{1 *}$, Afidah Abidin ${ }^{1,2}$, Premala Subramaniam ${ }^{3}$, Mohd \\ Fazeli Sazali ${ }^{1}$, Mohammad Saffree Jeffree ${ }^{1}$, Mazlinda Musa ${ }^{4}$, Nicholas Tze Ping Pang ${ }^{1}$, Azizan Omar ${ }^{1}$, \\ Mohd Faizal Madrim ${ }^{1}$, Khalid Mokti ${ }^{1}$, Abdul Rahman Ramdzan ${ }^{1}$, Zulkhairul Naim Sidek Ahmad ${ }^{1}$, Azman \\ Atil ${ }^{1}$, Muhammad Aklil Abd Rahim ${ }^{1}$ and Mohd Rohaizat Hassan ${ }^{5}$ \\ ${ }^{1}$ Department of Community Health and Family Medicine, Faculty Medicine and Health Sciences, \\ Universiti Malaysia Sabah, Malaysia \\ ${ }^{2}$ Tawau Area Health Office, Sabah State Health Department, Ministry of Health Malaysia \\ ${ }^{3}$ Queen Elizabeth Hospital Kota Kinabalu, Sabah State Health Department, Ministry of Health Malaysia \\ ${ }^{4}$ Department of Medical Education, Faculty Medicine and Health Sciences, Universiti Malaysia Sabah, \\ Malaysia \\ ${ }^{5}$ Department of Community Health, Faculty of Medicine, Universiti Kebangsaan Malaysia, Malaysia
}

Corresponding author: Syed Sharizman Syed Abdul Rahim

Email: syedsharizman@ums.edu.my

\begin{abstract}
The elderly population in Malaysia are multiplying, and older people's reliance on social services such as the elderly institutions has increased. Mental health problems especially depression is one of the main problems with institutionalized elderly. This study aims to determine the prevalence and associated risk factors of depression among elderly in all three state-run institutions in Sabah. A multi-centred, cross-sectional study was conducted on residents of all three state-run elderly institutions in Sabah $(N=110)$. All residents that fulfil the criteria were included in the study through a self-administered set of validated questionnaires that measure perceived social support, loneliness, and depression. Statistical Package for the Social Sciences by IBM (IBM SPSS) v25 was used and Chi Square and logistic regression for analysis. The prevalence of depressive symptoms is at $60.9 \%$. The independent risk factors for depression in residents were male gender $(O R=4.09,95 \% \mathrm{Cl}=1.55,10.79)$, perceived poor health status $(O R=6.63,95 \% \mathrm{Cl}=2.49$, 17.65), and loneliness $(O R=6.12,95 \% \mathrm{Cl}=2.02,18.53)$. Depression is prevalent among the elderly in the state-run institutions in Sabah, Malaysia. A comprehensive mental health screening program needs to be implemented for the elderly institutions along with adequate training for staff to handle mental health issues in the elderly.
\end{abstract}

Keywords: Depression, Elderly, Nursing homes

\section{INTRODUCTION}

The international population is ageing, the phenomenon occurring almost everywhere in the world. In 2017, the international population of people aged 60 years and over was 962 million, a double increase compared with 382 million in 1980. That figure projected to double by 2050 as forecast at 2.1 billion ${ }^{1}$. Like elsewhere in the world, the demographic profile of Malaysia's population has changed over the past two decades. The elderly are estimated to reach 14.5 $\%$ by 2040 , compared to $5.0 \%$ in 2010 , thereby classifying Malaysia as one of the fastest nations to enter the aged country in 20 years ${ }^{2}$.

The elderly reliance on social services such as an elderly home has increased over the past decade ${ }^{3}$. It is predicted that elderly residential care home will be the elderly's first choice as their preferred living arrangement in the coming decades, and demand for places in an elderly residential home will continue to grow as the elderly population is expanding ${ }^{4}$. However, there are also study that show the Malaysian generations prefers to age-in-place and live independently in their retirement life stage. Agerelated health problems affect common daily actions of the elderly and therefore emphasising the importance of elderly-friendly design ${ }^{5}$. Institutionalized elderly is at risk of psychiatric disorders, especially depression. Risk of depression increases in institutionalized elderly than those who live in the community, with their families. Elderly depression can be considered an essential public health issue. It is associated with increased morbidity, increased suicide risk, decreased physical, cognitive and social functioning, and greater self-neglect, all associated with increased mortality ${ }^{6}$.

There has been lack of studies done in relation to the population of elderly in Sabah, especially among the institutionalized. This study aims to determine the prevalence and associated risk factors of depression among the institutionalized elderly in Sabah, Malaysia Borneo. With the findings, this study could provide baseline information on the prevalence as well as rationale for future monitoring and intervention. 


\section{METHODS}

This multi-centred cross-sectional study involved the elderly residents of all three state-run elderly institutions home in Sabah, namely Sri Pritchard Kinarut Old-folks Home $(\mathrm{N}=51)$, Sri Harapan Sandakan Old-folks Home $(\mathrm{N}=38)$ and Air Panas Tawau Old-folks Home ( $\mathrm{N}=21)$. All 156 residents from all three old-folks home were initially planned to be included in the study. Respondents were recruited among those who fit into the inclusion criteria which are as follows: residents who aged 60 years and above, admitted to the elderly institution for at least one month, able to communicate sufficiently in English or Malay, and has no severe cognitive impairment (MMSE $\geq 9$ ). Total population sampling was the method of choice because the numbers of elderly institutions establishments in Sabah, mainly the state-run, are minimal. A total of 110 respondent were included that fitted inclusion criteria and gave consent to be included in the study. Those who are sixty years old and above, resident of the old-folks home for at least one month, able to communicate sufficiently in English or Malay and has no severe cognitive impairment (MMSE $\geq 9$ ).

A set of validated, a self-administered questionnaire which consists of six parts, sociodemographic, health status, specific questions, 14-item Malay Geriatric Depression Scale questionnaire (M-GDS-14), Malay Multidimensional Scale of Perceived Social Support (MSPSS-M) questionnaire and Malay version of De Jong Gierveld Loneliness Scale. A preliminary assessment by Malay Mini-Mental State Examination (M-MMSE) was done to assess the cognitive status of each potential respondent for their eligibility to be included in the study. The M-GDS-14 questionnaire was chosen as the primary tool to measure depressive symptoms in this study ${ }^{7}$.

The socio-demographic questionnaire included gender, age, ethnicity, education level, marital status, previous occupation, smoking status, and medical history. Participants were asked if they had any medical history of diabetes, hypertension, cardiovascular diseases, stroke, and arthritis while reviewing the medical records provided by the institutions. Respondents were asked a few specific questions regarding their perceived adequacy of care and also self-rating of their health status.

All items in the newly formed scale, M-GDS-14, had satisfactory corrected item-total correlation, with Cronbach's alpha coefficient of 0.84 . The score ranges from zero to 15 and a score of zero to four is considered to be within the normal range, five to nine indicates mild depression, and a score of 10 or more indicates moderate to severe depression. The M-GDS-14 questionnaire is chosen as the primary tool to measure depression in this study. The Multidimensional Perceived
Social Support Scale (MSPSS) developed by is one of the most extensively translated and validated tools to measure social support outcome. Any mean scale score of 1 to 2.9 could be considered low support; a score of 3 to 5 could be considered medium support; a score of 5.1 to 7 could be considered high support. The MSPSS-M demonstrated strong construct validity and reliability in measuring social support among older persons and could be used among older persons in Malaysia. MSPSS-M will be used as the tools to measure social support level among the respondents in this study.

The 6-item Malay version of De Jong Gierveld Loneliness scale consists of emotional subscale and social subscale, with three items on each scale is the tools to measure loneliness among participants in the study. Respondents rate their responses to statements on a 5-point Likert scale. A total score is calculated after subscale responses are recoded to account for negatively worded items, providing a range of zero (not lonely) to six (very lonely) or range from zero to three in each scale. This tool is a simple yet reliable and valid tool to measure emotional and social loneliness in the Malaysian context. Data was analysed by using the Statistical Package for the Social Sciences by IBM (IBM SPSS) version 25.

Descriptive analysis determined the mean, median and distribution of the continuous variables data (age), while categorical data were described in both count and percentage. The association between depressive symptoms with categorical variables were analysed using Chisquare $(\mathrm{x} 2)$ tests. Risk factors that were found to be significant $(p<0.05)$ with depressive symptoms were further analysed with multiple logistic regression.

The categorical risk factor variables (which have more than two answers) were then recoded into two groups each (according to the level of risk; higher and lower) for the bivariate analysis. The association between depression (which is determined by their score in M-GDS-14) with various variables which were hypothesised to be its associated risk factors (socio-demography, health-related, psychosocial, social support and loneliness) were also analysed using Chi-square $(\mathrm{x} 2)$ tests. Risk factors that were found to be significantly associated $(p<0.05)$ with depression in the initial analysis by using Chi-square (x2) tests were further analysed with multiple logistic regression to determine the significant predictors to depression in the population of the study. Factors which have shown significant association with depression in the bivariate analysis were further analysed using multiple logistic regression.

Data collection were conducted through a selfadministered set of questionnaires, administered by appointed and trained enumerators in each 
institution. set of questionnaires in the institutions from July 2020 till August 2020, after obtaining ethical approval from Ethics Committee of Universiti Malaysia Sabah [UMS JKEtika/1/20(29)], the endorsement from Sabah State Welfare Service Department and approval from respective centres.

\section{RESULTS}

The study population comprised of 68 (61.8\%) male and 42 (38.2\%) female. The mean age of the study participants was 70.92 years $(S D=7.74)$ with the minimum age was 60 years, and the maximum age was 94 years. About $20 \%$ of the respondents had no formal education, and more than half ( 54.5 $\%$ completed primary education. For marital status, $6.4 \%$ were married and living with their spouses while the majority were either unmarried or widowed.

Majority of the residents (74.5\%) are ADLindependent while the rest $(25.5 \%)$ are bed-ridden and needing care assistance for activities of daily living (ADL-dependent). Only $42.7 \%$ of respondents rated their health status as good, while $21.8 \%$ perceived their health status as poor. Around a quarter of the residents are still actively smoking. Only 31 (28.2\%) have no chronic disease. Most of the residents $(45.5 \%)$ have one to two chronic diseases and $24.5 \%$ with three to four chronic diseases.

Nearly half of the respondents in the study (46.4\%) had resided in the elderly institution for more than five years. Nearly two-third $(65.5 \%)$ of the residents were admitted to the elderly institution by their self-will, while the rest of $34.5 \%$ admitted by compulsion, whether by family choice or others, e.g. recommendation of the medical practitioner, social worker, friends or transferred from other healthcare facilities. Around 36\% of the residents claimed that they had not received any visitors since entering the institution. Up to half $(49.1 \%)$ of the respondents said that they are spending time with other residents every day. When they were asked whether they wanted to stay in the elderly institution or to leave, the majority of them $(73.6 \%)$ responded they wanted to stay in.

Among the respondents, $13(11.8 \%)$ perceived their social support level as high, and only $16.4 \%$ or 18 respondents perceived their social support level as low. Majority of the respondents $(71.8 \%)$ perceived medium level of social support. A total of 81 residents $(73.6 \%$ ) classified as lonely in the study. Prevalence of depressive symptoms found to be at $60.9 \%$, where 67 out the 110 respondents were classified as clinically significantly depressed; among those, $19(17.3 \%)$ were moderate to severely depressed and 48 (43.6\%) with mild depression.

On further analysis, the study found that there is an association of gender $\left(x^{2}=14.85, p<0.001\right)$, with depression among the studied subject of elderly residents of the state-run elderly institutions in Sabah. Male residents are 4.88 times more likely to develop depression as compared to their female counterparts $(\mathrm{OR}=4.88, \quad 95 \% \mathrm{Cl}=2.13$, 11.18). On the contrary, the study found no association between depression and other sociodemographic risk factors which were analysed; age $\left(x^{2}=2.66, p=0.103\right)$, marital status $\left(x^{2}=3.21\right.$, $p=0.073)$ and level of education $\left(x^{2}=0.85\right.$, $\mathrm{p}=0.357$ ) (Table 1).

Table 1 : Chi Square analysis showing the association between different socio-demographic risk factors with depression among the respondents

\begin{tabular}{|c|c|c|c|c|c|c|}
\hline \multicolumn{2}{|c|}{$\begin{array}{l}\text { Socio-demographic risk } \\
\text { factors }\end{array}$} & \multirow{2}{*}{$\begin{array}{l}\text { Not } \\
\text { Depressed } \\
\text { n (\%) } \\
26(61.90)\end{array}$} & \multirow{2}{*}{$\begin{array}{l}\text { Depressed } \\
\text { N (\%) } \\
16(38.10)\end{array}$} & \multirow[t]{2}{*}{ OR $(95 \% \mathrm{Cl})$} & \multirow[t]{2}{*}{$x^{2}$} & \multirow[t]{2}{*}{$\mathrm{p}$-value } \\
\hline Gender & Female & & & & & \\
\hline & Male & $17(25.00)$ & $51(75.00)$ & $4.88(2.13,11.18)$ & & \\
\hline \multirow[t]{2}{*}{ Marital Status } & $\begin{array}{l}\text { With } \\
\text { Partner }\end{array}$ & $0(0)$ & $7(100)$ & & 14.85 & $.000^{*}$ \\
\hline & $\begin{array}{l}\text { No } \\
\text { Partner }\end{array}$ & $43(41.70)$ & $60(58.30)$ & & 3.21 & 0.073 \\
\hline \multirow[t]{2}{*}{$\begin{array}{l}\text { Level of } \\
\text { Education }\end{array}$} & $\begin{array}{l}\text { Higher } \\
\text { Level }\end{array}$ & $13(46.40)$ & $15(53.60)$ & & & \\
\hline & $\begin{array}{l}\text { No/Low } \\
\text { Level }\end{array}$ & $30(36.60)$ & $52(63.40)$ & $1.50(0.63,3.58)$ & 0.85 & 0.357 \\
\hline
\end{tabular}

* significant at the .05 level

For health-related risk factors (Table 2), several variables were found to have a significant association with depression among studied subjects namely status of care or ADL status $\left(x^{2}=4.92, p=.027\right)$, presence of chronic disease $\left(x^{2}=6.52, p=.011\right)$, perceived or self-rated health status by the respondent $\left(x^{2}=21.09, p=.000\right)$ and perceived adequacy of care $\left(x^{2}=4.15, p=.042\right)$. History of smoking $\left(x^{2}=0.95, p=0.331\right)$, and the number of chronic diseases $\left(x^{2}=1.07, p=0.3\right)$ were 
found not to be statistically associated with depression among the elderly subjects. Residents who are $A D L$-dependent $(\mathrm{OR}=3.02,95 \% \mathrm{Cl}=1.11$, 8.21) are most likely to be depressed by 3.02 times compared to those who are ADLindependent. The elderly institution residents who rated their health status as not good found to be 6.79 times more likely to develop depression compared to those who feel their health status is functional $\quad(\mathrm{OR}=6.79, \quad 95 \% \mathrm{Cl}=2.89, \quad 15.92)$. Residents who feel that they did not receive adequate care are 4.47 times more likely to be depressed than those who perceived adequate care $(\mathrm{OR} 4.47=, 95 \% \mathrm{Cl}=0.95,21.09)$.

Table 2: Chi Square analysis showing the association between different health-related risk factors with depression among the respondents

\begin{tabular}{|c|c|c|c|c|c|c|}
\hline \multicolumn{2}{|c|}{ Health-related risk factors } & \multirow{2}{*}{$\begin{array}{l}\begin{array}{l}\text { Not } \\
\text { Depressed } \\
\text { n (\%) } \\
37(45.10)\end{array} \\
\end{array}$} & \multirow{2}{*}{$\begin{array}{l}\text { Depressed } \\
\text { n (\%) } \\
45(54.90)\end{array}$} & \multirow[t]{2}{*}{ OR $(95 \% \mathrm{Cl})$} & \multirow[t]{2}{*}{$x^{2}$} & \multirow[t]{2}{*}{ p-value } \\
\hline ADL Status & $\begin{array}{l}\mathrm{ADL} \\
\text { Independent }\end{array}$ & & & & & \\
\hline & ADL Dependent & $6(21.40)$ & $22(78.60)$ & $3.02(1.11,8.21)$ & 4.92 & $.027^{*}$ \\
\hline \multirow{2}{*}{$\begin{array}{l}\text { Chronic } \\
\text { diseases }\end{array}$} & No & $18(58.10)$ & $13(41.90)$ & & & \\
\hline & Yes & $25(31.60)$ & $54(68.40)$ & $2.99(1.27,7.04)$ & 6.53 & $.011^{*}$ \\
\hline $\begin{array}{l}\text { No. of chronic } \\
\text { diseases }\end{array}$ & $\begin{array}{l}<3 \text { Chronic } \\
\text { Diseases } \\
\geq 3 \text { Chronic } \\
\text { Diseases }\end{array}$ & $\begin{array}{l}34(42.00) \\
9(31.00)\end{array}$ & $\begin{array}{l}47(58.00) \\
20(69.00)\end{array}$ & $1.61(0.65,3.96)$ & 1.07 & 0.3 \\
\hline \multirow{2}{*}{$\begin{array}{l}\text { History of } \\
\text { smoking }\end{array}$} & Never smoke & $29(42.60)$ & $39(57.40)$ & & & \\
\hline & $\begin{array}{l}\text { Smoker/ex- } \\
\text { smoker }\end{array}$ & $14(33.30)$ & $28(66.70)$ & $1.49(0.67,3.31)$ & 0.95 & 0.331 \\
\hline \multirow{2}{*}{$\begin{array}{l}\text { Perceived } \\
\text { health status }\end{array}$} & Good & $30(63.80)$ & $17(36.20)$ & & & \\
\hline & Not good & $13(20.60)$ & $50(79.40)$ & $6.79(2.89,15.92)$ & 21.09 & $.000^{*}$ \\
\hline \multirow{2}{*}{$\begin{array}{l}\text { Perceived } \\
\text { adequacy of } \\
\text { care }\end{array}$} & Yes & $41(42.70)$ & $55(57.30)$ & & & \\
\hline & No & $2(14.30)$ & $12(85.70)$ & $4.47(0.95,21.09)$ & 4.15 & $.042^{*}$ \\
\hline
\end{tabular}

${ }^{*}$ significant at the .05 level

The study found insufficient statistical evidence to associate length of stay in the elderly institutions, receiving visitors, time spent with fellow residents with depression among the respondents. Reason of admission to the elderly institutions $\left(x^{2}=3.98, p=0.419\right)$, and loneliness $\left(x^{2}=11.55, p=.001\right)$ are among the psychosocial risk factor that found to be associated with depression among the elderly. Compulsion as the reason of the admission of a resident to the elderly institutions whether by family members, friends or due to medical decision increase the odds of depression by 2.37 times compared to admission by resident self-will $(\mathrm{OR}=2.37$, $95 \% \mathrm{Cl}=1.01,5.59)$. It took us by surprise that there is no statistical association found between the level of social support with depression among the subjects of the study $\left(x^{2}=0.3, p=0.58\right)$. It was evidenced that in the study, residents who are experiencing loneliness are more predisposed to depression by 4.51 times more than residents who do not. (Table 3 ).

The results of multiple logistic regression analysis is shown in Table 4. In summary, the independent risk factors for depression among the residents based on multiple logistic regression were identified as male gender $(\mathrm{OR}=4.09,95 \% \mathrm{Cl}=1.55$, 10.79), perceived poor health status $(O R=6.63$, $95 \% \mathrm{Cl}=2.49,17.65)$, and loneliness $(\mathrm{OR}=6.12$, $95 \% \mathrm{Cl}=2.02,18.53)$.

\section{DISCUSSION}

From the study, the prevalence of depressive symptoms were high $(60.9 \%)$ with factors such as male gender, perceived poor health status and loneliness were associated with depressive symptoms among elderly in a state-run institutions in Sabah, Malaysia. The prevalence of depression in elderly residents of nursing homes was demonstrated to be in between $20 \%$ to $70 \%$ in the literature ${ }^{8-10}$. An earlier local study carried out by on residents of the state-run elderly institution in Kedah, Malaysia found a prevalence of depression among the residents was $67 \%$, which was similar findings with our study. depression is often missed in the elderly in residential care ${ }^{11}$. Female gender is associated with depression among elderly home residents as demonstrated by several previous studies ${ }^{12,13}$. However, we have demonstrated a significant association between 
gender to depression among the studied subjects in our initial analysis where male residents are about 4 times more likely to develop depression as compared to their female counterparts. Males may exhibit more depressive symptoms as they have network crisis and vulnerable to network events after retirement. They may also have more relationship problems. Meanwhile, women have more tendencies to look for social support compared to men ${ }^{9}$. Perceived health status was found to be significantly associated with depression in the elderly ${ }^{14,15}$. In a study among Japanese elderly, it was revealed that the elderly who perceived their health status as not good were more depressed ${ }^{16}$.

Table 3: Chi Square analysis showing the association between different psychosocial risk factors, social support and loneliness with depression among the respondents

\begin{tabular}{|c|c|c|c|c|c|c|}
\hline \multicolumn{2}{|c|}{ Psychosocial risk factors } & \multirow{2}{*}{$\begin{array}{l}\begin{array}{l}\text { Not } \\
\text { Depressed } \\
n\end{array} \\
21(35.60)\end{array}$} & \multirow{2}{*}{$\begin{array}{l}\text { Depressed } \\
\text { n } \\
38(64.40)\end{array}$} & \multirow[t]{2}{*}{ OR $(95 \% \mathrm{Cl})$} & \multirow[t]{2}{*}{$x^{2}$} & \multirow[t]{2}{*}{ p-value } \\
\hline Length of Stay & $<5$ Years & & & & & \\
\hline & $\geq 5$ Years & $22(43.10)$ & $29(56.90)$ & $0.73(0.34,1.57)$ & 0.65 & 0.419 \\
\hline \multirow{2}{*}{$\begin{array}{l}\text { Reason of } \\
\text { admission to } \\
\text { OFH }\end{array}$} & Self-will & $33(45.80)$ & $39(54.20)$ & & & \\
\hline & Compulsion & $10(26.30)$ & $28(73.70)$ & $2.37(1.01,5.59)$ & 3.98 & $.046^{*}$ \\
\hline \multirow{2}{*}{$\begin{array}{l}\text { Receiving } \\
\text { visitors }\end{array}$} & Yes & $28(40.00)$ & $42(60.00)$ & & & \\
\hline & No & $15(37.50)$ & $25(62.50)$ & $1.11(0.50,2.47)$ & 0.07 & 0.796 \\
\hline \multirow{4}{*}{$\begin{array}{l}\text { Spending time } \\
\text { with a } \\
\text { colleague } \\
\text { Level of Social } \\
\text { Support }\end{array}$} & Always & $25(46.30)$ & $29(53.70)$ & & & \\
\hline & Never/Rarely & $18(32.10)$ & $38(67.90)$ & $1.82(0.84,3.95)$ & 2.31 & 0.128 \\
\hline & $\begin{array}{l}\text { Medium or } \\
\text { High Support }\end{array}$ & $37(40.20)$ & 55 (59.80) & & & \\
\hline & Low Support & $6(33.30)$ & $12(66.70)$ & $1.35(0.46,3.90)$ & 0.30 & 0.584 \\
\hline \multirow[t]{2}{*}{ Loneliness } & No & $19(65.50)$ & $10(34.50)$ & & & \\
\hline & Yes & $24(29.60)$ & $57(70.40)$ & $4.51(1.83,11.12)$ & 11.55 & $.001^{*}$ \\
\hline
\end{tabular}

Health-promoting lifestyle has been found to be an important influencing factor of elderly depression. The aging perceptions are an important mediating role in the relationship between health-promoting lifestyle and elderly depression. Furthermore, social support may moderate between aging perceptions and elderly depression together with a high level of social support ${ }^{17}$. It is intriguing to note that although the presence of chronic diseases and numbers of chronic diseases did not differ significantly between the depressed and non-depressed respondents in our multivariate analysis, perceived poor health status remains a significant risk factor for depressive symptoms.

On the other hand, lower self-rated health was found to predict premature discontinuation of treatment for chronic disease, including depression ${ }^{18}$. In this study, similar findings on loneliness were also seen in nursing home residents in Korea and Japan ${ }^{19}$. Depression was influenced by loneliness and general health status 14,15 .
Preventing depression should be the main aim of designing a care program for patients in a nursing home. With evolving technology, newer innovate ways needs to be explore as healthcare transformation should involve the home and as well as institutional community setting in order to bring the healthcare services to patients ${ }^{20}$. This is the first-ever study to investigate the prevalence and risk factors associated with depression in elderly residents in Sabah. This study is not without its limitations. Although the sample investigated was relatively small, but it is representative of the whole state-run elderly institutions in Sabah. Besides that, those with $M M S E<9$ were excluded from the study, and this means that a number of our residents were not assessed or included in figures for the prevalence of depression. This was a cross sectional study and only limited on state-run elderly institution in Sabah and thus cannot be generalized. The study showed the association in between depressive symptoms and some risk factors, however causation cannot be ascertained. 
Table 4: Results of the final model of multiple logistic regression

\begin{tabular}{lccccccccc}
\hline \multirow{2}{*}{$\begin{array}{l}\text { Risk factor } \\
\text { B }\end{array}$} & SE. & Wald & df & p-value & aOR & \multicolumn{2}{c}{$95 \% \mathrm{Cl}$} \\
\hline Gender (male) & 1.409 & 0.495 & 8.109 & 1 & 0.004 & 4.091 & 1.551 & 10.786 \\
Perceived health Status (not good) & 1.892 & 0.500 & 14.339 & 1 & 0.000 & 6.631 & 2.491 & 17.653 \\
Loneliness & 1.811 & 0.566 & 10.250 & 1 & 0.001 & 6.116 & 2.018 & 18.534 \\
Constant & -2.696 & 0.677 & 15.880 & 1 & 0.000 & 0.067 & & \\
\hline
\end{tabular}

\section{CONCLUSION}

This study demonstrated that depressive symptoms is highly prevalent among the elderly in state-run institution in Sabah, Malaysia. An appropriate multidisciplinary intervention in addressing both health and social problems of the elderly may benefit the residents in the future. Given the results of this study, a strong suggestion that a comprehensive mental health screening program to be implemented for the elderly institutions along with adequate training for staff to handle mental health issues in the elderly.

\section{Conflict of interest}

The authors declare no potential conflict of interest.

\section{Acknowledgements}

This work would not have been possible without the support of the Sabah State Department of Welfare Services. We would also like to thank Sri Harapan Old-folks Home Sandakan, Sri Pritchard Old-folks Home Kinarut and Air Panas Old-folks Home Tawau for facilitating with the data collection procedures in their respective establishments.

\section{REFERENCES}

1. United Nations. (No Title). World Population Ageing. https://www.un.org/en/development/des a/population/publications/pdf/ageing/WP A2017_Highlights.pdf. Published 2017. Accessed October 10, 2020.

2. DOSM. DEPARTMENT OF STATISTICS MALAYSIA PRESS RELEASE ABRIDGED LIFE TABLES, MALAYSIA, 2017-2019.; 2019.

3. Doumit J, Nasser R. Quality of life and wellbeing of the elderly in Lebanese nursing homes. Int J Health Care Qual Assur. 2010;23(1):72-93. doi:10.1108/09526861011010695

4. Zm L, Kamal M. Prevalence of Demographic Profiles and Loneliness among Elderly Women in Private Care Institution The Effects of Talent Management Towards Job
Satisfaction and Performance Management among Academicians in Selected Publis Higher Learning Institutions View project Prevalence of Demographic Profiles and Loneliness among Elderly Women in Private Care Institution. Artic Indian J Public Heal Res Dev. 2020;11(6). doi:10.37506/ijphrd.v11i6.10008

5. Ismail H, Nordin MSA, Zainan Abidin AW. The Elderly-Friendly Housing Design Features Preferences by Generations in Malaysia. Environ Proc J. 2020;5(15):141148. doi:10.21834/ebpj.v5i15.2510

6. Jongenelis K, Pot AM, Eisses AMH, Beekman ATF, Kluiter $\mathrm{H}$, Ribbe MW. Prevalence and risk indicators of depression in elderly nursing home patients: The AGED study. $J$ Affect Disord. 2004;83(2-3):135-142. doi:10.1016/j.jad.2004.06.001

7. Conradsson $M$, Rosendahl $E$, Littbrand $H$, Gustafson $Y$, Olofsson B, Lövheim $H$. Usefulness of the Geriatric Depression Scale 15 -item version among very old people with and without cognitive impairment. Aging Ment Health. 2013;17(5):638-645. doi:10.1080/13607863.2012.758231

8. Manungkalit M, Putu Wulan Purnama Sari N. The Influence of Anxiety and Stress toward Depression in Institutionalized Elderly. Vol 9.; 2020.

9. Shrestha K, Ojha SP, Dhungana S, Shrestha $S$. Depression and its association with quality of life among elderly: An elderly home- cross sectional study. Neurol Psychiatry Brain Res. 2020;38:1-4. doi:10.1016/j.npbr.2020.08.003

10. Pramesona BA, Taneepanichskul S. Prevalence and risk factors of depression among Indonesian elderly: A nursing homebased cross-sectional study. Neurol Psychiatry Brain Res. 2018;30:22-27. doi:10.1016/j.npbr.2018.04.004

11. Al-Jawad M, Rashid AK, Narayan KA. Prevalence of undetected cognitive 
impairment and depression in residents of an elderly care home. Med J Malaysia. 2007;62(5):375-379.

12. Xiang $\mathrm{X}$, Danilovich MK, Tomasino KN, Jordan N. Depression prevalence and treatment among older home health services users in the United States. Arch Gerontol Geriatr. 2018;75(February 2017):151-157.

doi:10.1016/j.archger.2017.12.005

13. Pramesona BA, Taneepanichskul S. Prevalence and risk factors of depression among Indonesian elderly: A nursing homebased cross-sectional study. Neurol Psychiatry Brain Res. 2018;30(November 2017):22-27.

doi:10.1016/j.npbr.2018.04.004

14. Cacioppo JT, Hughes ME, Waite LJ, Hawkley LC, Thisted RA. Loneliness as a specific risk factor for depressive symptoms: Crosssectional and longitudinal analyses. Psychol Aging. 2006;21(1):140-151. doi:10.1037/0882-7974.21.1.140

15. Tiikkainen $\mathrm{P}$, Heikkinen R-L. Associations between loneliness, depressive symptoms and perceived togetherness in older people. Aging Ment Health. 2005;9(6):526534. doi:10.1080/13607860500193138

16. Rauch SAM, Morales KH, Zubritsky C, Knott $\mathrm{K}$, Oslin D. Posttraumatic stress, depression, and health among older adults in primary care. Am J Geriatr psychiatry Off $J$ Am Assoc Geriatr Psychiatry. 2006;14(4):316-324.

doi:10.1097/01.JGP.0000199382.96115.86

17. Zhou W, Chen D, Hong Z, Fan H, Liu · Shen, Zhang $\mathrm{L}$. The relationship between healthpromoting lifestyles and depression in the elderly: roles of aging perceptions and social support. 2021;30:721-728. doi:10.1007/s11136-020-02674-4

18. Lenze EJ, Miller MD, Dew MA, et al. Subjective health measures and acute treatment outcomes in geriatric depression. Int $J$ Geriatr Psychiatry. 2001;16(12):1149-1155.

doi:10.1002/gps.503

19. Kim O, Byeon YS, Kim JH, Endo E, Akahoshi $\mathrm{M}$, Ogasawara $\mathrm{H}$. Loneliness, depression and health status of the institutionalized elderly in Korea and Japan. Asian Nurs Res (Korean Soc Nurs Sci). 2009;3(2):63-70. doi:10.1016/S1976-1317(09)60017-7

20. Jeffree MS, Ahmedy $F$, Avoi $R$, et al. Integrating digital health for healthcare transformation: Conceptual model of smart healthcare for northern Borneo. Int J Adv Trends Comput Sci Eng. 2020. doi:10.30534/ijatcse/2020/17912020 